\title{
Detection of DNA Sequence Variation via Deliberate Heteroduplex Formation from Genomic DNAs Amplified en masse in "Population Tubes"
}

\author{
Gualberto Ruano, ${ }^{1}$ Amos S. Deinard, Sarah Tishkoff, and Kenneth K. Kidd
}

Department of Genetics, Yale University School of Medicine, New Haven, Connecticut 06510

\begin{abstract}
We have developed the population tube (poptube) system for sensitive detection and large-scale sampling of DNA sequence variation in several human populations of wide geographic distribution. In this methodology, genomic DNAs from five individuals in a population are PCR amplified en masse to maximize deliberately the chances of forming heteroduplexes among allelic variants. Interpopulation mixing is performed in a separate set of tubes containing one individual from each of five populations as well as a reference chimpanzee sample deliberately chosen to be different from all humans. Mismatches at sites of allelic variation retard the electrophoresis and reduce the stability of heteroduplex molecules. The products are electrophoresed on denaturing gradient gels where detection of heteroduplexes is accomplished readily. Using poptubes, we have discovered a rare variant in an otherwise highly conserved 440-bp segment in the long intron of the glucose-6-phosphate dehydrogenase (G6PD) gene. The polymorphism at this X-chromosome locus could be only detected in males by mixing samples, as homoduplexes for both alleles co-focus on denaturing gradient electrophoresis.
\end{abstract}

'Current address: Molecular Genetics Group, BIOS Laboratories, 5 Science Park, New Haven, Connecticut 06511.
D etection of DNA sequence variants is essential for many population and medical genetics studies. The relative merits and disadvantages of a variety of molecular scanning methods have been recently reviewed. ${ }^{(1,2)}$ The two main concerns in any large-scale scanning of multiple DNA loci are sensitivity of detection and throughput of samples.

Detection of DNA sequence variants by formation of heteroduplex molecules is highly sensitive. Both RNA/DNA and DNA/DNA heteroduplexes had been exploited previously on cloned and ge nomic DNA to detect $\beta$-thalassemia variants. ${ }^{(3-5)}$ Deliberate DNA/DNA heteroduplex formation is also the basis of the chemical cleavage technique. ${ }^{6,7}$ )

PCR-generated heteroduplexes, although described at first as an unforeseen artifact, ${ }^{(8)}$ have now been shown to be unequivocal indicators of polymorphisms $^{(9)}$ and of mutations in hemophilia A (factor VIII gene), ${ }^{(10,11)}$ $\beta$-thalassemia, ${ }^{(12)}$ retinitis pigmentosa, ${ }^{(13)}$ sickle-cell anemia, ${ }^{(14)}$ and p53 oncogenesis. $^{(15,16)}$ PCR-generated heteroduplexes are relatively easy to detect electrophoretically because their formation leads to blurred or extra bands on gels. Heteroduplexes bear mismatched bases at allelic or mutated sites, which reduces both their electrophoretic mobility and inherent stability (Fig. 1)

We have developed "population tubes" or "poptubes," a system wherein heteroduplex formation is planned deliberately. In this methodology, genomic DNA samples from different individuals are amplified simultaneously at a given locus. As a first step in the devel- opment of the poptube system, we had analyzed both the amplification of a given DNA segment from complex mixtures of genomic DNA templates and the resolution of the PCR products on denaturing gradient gels. ${ }^{(1)}$ These experiments demonstrated that PCR can amplify mixed allelic templates in direct proportion to the stoichiometric fraction of each template and that heteroduplexes are displaced clearly on the gel from the dominant homoduplex species.

The poptube system achieves seemingly antagonistic goals essential for large-scale sampling: it simplifies and accelerates the search for DNA variants while increasing the sensitivity of the molecular scan. Using poptubes, we have discovered a rare variant in a 440 bp segment in the long intron of the glucose-6-phosphate dehydrogenase (G6PD) gene.

\section{MATERIALS AND METHODS \\ Design of Poptubes}

We had found that detection of a "trace" allele mixed with a "dominant" one was possible by simple ethidium bromide staining of the gel up to a sensitivity of 1 part in $20 .^{(17)}$ To keep detection within those bounds, the poptube system was designed to have the least common allele in a pool represented by at least 1 part in 10 . We also had found that all predicted heteroduplexes in bi- and triallelic DNA mixtures were resolved despite differences of only 1,2 , or 3 base pairs among alleles. ${ }^{(9,17)}$

Poptubes contain genomic DNA from five individuals, either three males and 


\section{HETERODUPLEXES}

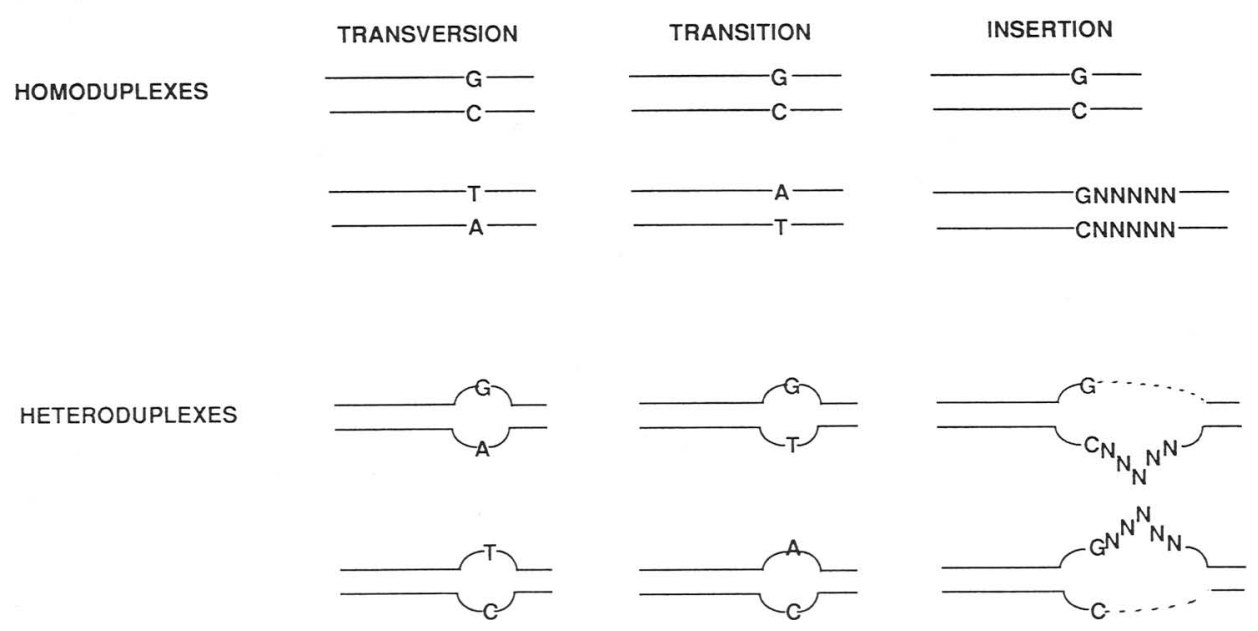

FIGURE 1 Types of heteroduplexes. There are four kinds of heteroduplex molecules resulting from transversions, transitions, and insertions in DNA sequences. The top duplex in each column is the original homoduplex sequence. The second duplex incorporates the postulated mutational event. The last two duplexes represent the two heteroduplexes resulting from mismatched appositions to either of the strands in the original homoduplex. Heteroduplexes resulting from a transversion event will be of two kinds: in one type mismatched purines are apposed; in the other, mismatched pyrimidines. Heteroduplexes resulting from transitions will consist of mismatched purine/pyrimidine apposition. Heteroduplexes resulting from insertion/deletion events will consist of one area where the two strands have no complementary sequence; the region without complement will likely protrude out of the main axis of the double helix.

two females or two males and three females. Thus, the number of autosome chromosomes is 10 per pool, while the number of $\mathrm{X}$ chromosomes in any pool is either 7 or 8 . We have also created "United Nations tubes" (UN-tubes), pools containing DNA of one male individual from each of five different and geographically widely dispersed populations (Fig. 2). The individual used in the UN-tubes to represent a specific population is part of the pool of templates in the Poptube for his/her respective population. UN-tubes also contain a trace amount of DNA from a reference sample deliberately chosen to be different from all humans, for example, a male chimpanzee. UN-tubes exploit evolutionary relationships as an analytical tool. The chimpanzee genome is evolutionarily close enough to the human genome to allow human primers to anneal and amplify a chimpanzee target efficiently. Yet, at the same time, the chimpanzee genome is sufficiently divergent from the human to have nucleotide differences for most sequences of $>100 \mathrm{bp}$. The resulting human/chimpanzee (HuChi) heteroduplexes melt in the same gradi- ent range expected for human/human heteroduplexes resulting from polymorphism.

The design of poptubes and UN-tubes accounts for several possible modes of allelic distribution in populations (Fig. 3 ). The simplest case in a poptube is a bi-allelic mixture of even distribution with two clearly resolved homoduplexes and two heteroduplexes. If the homoduplexes are resolved clearly, but one of the alleles is infrequent, the trace allele will be captured as a heteroduplex and will not be discernible as homoduplex. In some cases, the homoduplexes will cofocus and be detected as a single band. DNA sequence variation in this case is only detectable by heteroduplex formation.

In some small isolated populations it is possible that genetic variation is minimal or that an allele globally rare is the common allele for that population. In such a case, heteroduplex formation might not be seen in a sample containing only five individuals. If another population evidences a different but co-focusing allele, DNA sequence variation would not be detected in the survey of poptubes alone unless mixing of DNA samples across populations is also incorporated.

Mixing of DNA samples from different populations is performed in the UNtubes, which link individual poptubes. Any allele not detected in poptubes, by default constitutes a trace allele in a UNtube. The human trace allele will form heteroduplex with the dominant human allele. The dominant human allele and the trace chimpanzee allele form a $\mathrm{Hu}$ Chi heteroduplex. The chimpanzee allele thus serves as a cross-referencing standard among UN-tubes. Constancy of the HuChi heteroduplex across all four UN-tubes indicates that the dominant human allele is the same across the world.

\section{Preparation of Poptubes and UN-Tubes}

DNA samples were extracted from lymphoblastoid cells established by EpsteinBarr transformation of B lymphocytes harvested from whole blood. The poptube system consists of 19 poptubes numbered for and representing 19 different populations throughout the world and of four UN-tubes. The DNA samples are selected from the Yale/Stanford repository for studies of human DNA sequence variation (K.K. Kidd and L.L. Cavalli-Sforza). The populations included in the survey were: (1) Biaka Pygmies, (2) Mbuti Pygmies, (3) Yemenite Jews, (4) Druze, (5) Ethiopian Jews, (6) Roman Jews, (7) Sardinians, (8) Thoti Indian, (9) Assamese, (10) Cambodian, (11) Chinese, (12) Japanese, (13) Nasioi Melanesians, (14) mixed European, (15) Moskoke Amerindian, (16) Maya, (17) Colombian Amerindian, (18) Karitana, and (19) Rondonia Surui. The populations included in the UN-tubes were as follows: UN 1-Chimpanzee (Colin), Ethiopian Jews, Druze, Sardinians, Rondonia Surui, Mbuti Pygmies; UN 2-Chimpanzee (Colin), Yemenite Jews, Chinese, Cambodians, Karitana, Biaka Pygmies; UN 3-Chimpanzee (Colin), Roman Jews, Assamese, Thoti Indian, Maya, mixed European; UN 4-Chimpanzee (Colin), Japanese, Moskoke Amerindian, Colombian, Nasioi Melanesians, mixed European.

Poptubes were prepared as follows. A genomic DNA amount of $12 \mu \mathrm{g}$ from each of five individuals was diluted to a final volume of $600 \mu \mathrm{l}$ with distilled wa- 


\section{POP TUBES}

5 INDIVIDUAL DNAS POOLED PER POPULATION

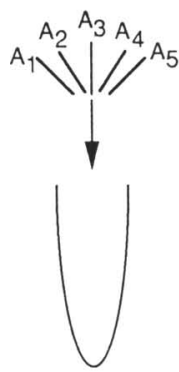

POP A

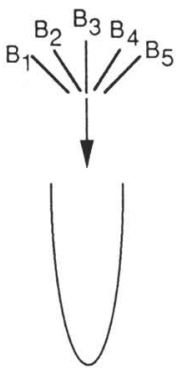

POP B

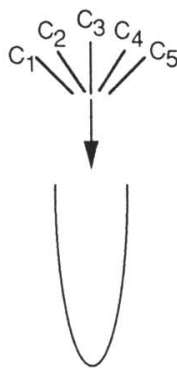

POP C

\section{U.N. TUBES}

5 INDIVIDUAL DNAS, EACH FROM A DIFFERENT POPULATION, PLUS REFERENCE TRACE CHIMPANZEE DNA

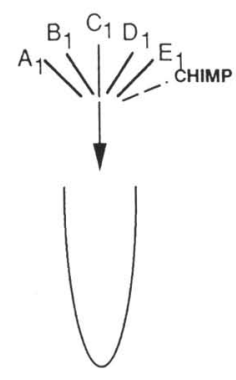

U.N.1

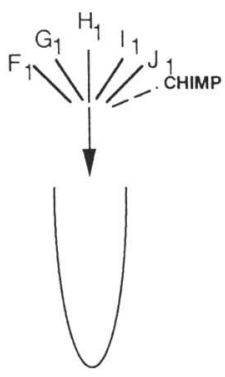

U.N.2

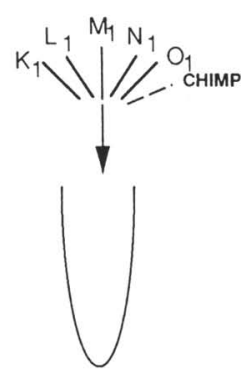

U.N.3

FIGURE 2 Genomic DNA pooling in the design of population tubes and UN-tubes. The logic behind the population/UN-tube system is deliberate heteroduplex formation through amplification from composite genomic template. (Upper panels) The survey of DNA sequence variation employs population tubes (Pop tubes), pools of whole genomic DNA containing five individuals from each of 19 populations. (Lower panels) UN-tubes pool DNA of one individual from each of five different populations to facilitate formation of interpopulation heteroduplexes. This pool also contains a trace amount of DNA from a reference chimpanzee.

ter. The concentration of individual DNAs is thus, $20 \mathrm{ng} / \mu \mathrm{l}$; that of total pooled DNA, $100 \mathrm{ng} / \mu \mathrm{l}$. For each amplification reaction, $10 \mu \mathrm{l}$ of Poptube DNA was used which is equivalent to a template amount of $200 \mathrm{ng}$ for each individual and $1 \mu \mathrm{g}$ for pooled genomic DNA.

For preparation of UN-tubes, $12 \mu \mathrm{g}$ genomic DNA from each of five individuals and $6 \mu \mathrm{g}$ genomic DNA from chimpanzee (Colin) were diluted to a final volume of $600 \mu \mathrm{l}$ with distilled water. The concentration of individual human DNAs is thus, $20 \mathrm{ng} / \mu \mathrm{l}$, the same as for poptubes; that for chimpanzee DNA is 10 $\mathrm{ng} / \mu \mathrm{l}$; that of total pooled DNA, $110 \mathrm{ng} /$ $\mu 1$. For each amplification reaction, $10 \mu \mathrm{l}$ of UN-tube DNA was used which is equivalent to a template amount of 200 $\mathrm{ng}$ for each human and $100 \mathrm{ng}$ for the chimpanzee. The ratio of total human to chimpanzee DNA is $10: 1$ in each reaction.

\section{Description and PCR Amplification of the G6PD Locus}

The G6PD gene maps to human chromosome Xq28 and spans close to $20 \mathrm{~kb}$. The second intron of the gene is quite large, $\sim 10 \mathrm{~kb}$. We selected a 440-bp fragment located midway through the large intron because melt map analysis of the sequence revealed a well-demarcated upper melting domain at one end of the segment and a similarly well-defined lower melting domain at the other with melting temperatures $4^{\circ} \mathrm{C}$ apart. ${ }^{(18)}$ (DNA sequence is a personal communication of Dr. Michele D'Urso.)

We synthesized the fragment with primers G6PD1 (5'-GCT GGG CCC CTG CCA AG-3' and G6PD2 (5'-ATG GGA AGA CAT CGG GAA AC-3'). PCR was performed in a $100-\mu l$ reaction mixture that included 10 picomoles of each primer (final concentration, $0.1 \mu \mathrm{M}$ each), 200 $\mu \mathrm{M}$ of each deoxynucleotide (Pharmacia), 2 units Taq polymerase (PerkinElmer AmpliTaq), $50 \mathrm{~mm} \mathrm{KCl}, 1.5 \mathrm{~mm}$ $\mathrm{MgCl}_{2}, 10 \mathrm{~mm}$ Tris (pH 8.4), $0.01 \%$ gelatin, overlayed with mineral oil. As template, the reactions utilized either $1 \mu \mathrm{g}$ pooled poptube genomic DNA (containing $200 \mathrm{ng}$ from each of five individuals) or $1 \mu \mathrm{g}$ individual genomic DNA. PCR was performed in a programmable thermal cycler (Perkin Elmer 480) for $30 \mathrm{cy}$ cles each consisting of 1-min denaturation at $94^{\circ} \mathrm{C}, 1-\mathrm{min}$ annealing at $60^{\circ} \mathrm{C}$, and $1-$ min polymerization at $72^{\circ} \mathrm{C}$.

\section{Denaturing Gradient Electrophoresis (DGE)}

Linear gradients of denaturants on $8 \%$ acrylamide and $1 \times$ TAE are poured ranging from $20 \%$ to $70 \%$ of a reference solution prepared at $40 \%$ (vol/vol) formamide and $7 \mathrm{~m}$ urea. Melt map predictions and empirical observations established this range of denaturants for best resolution of the fragments. Denaturants thus ranged from $\sim 1.4 \mathrm{M}$ urea and $8 \%$ formamide at the top of the gel, to $4.9 \mathrm{M}$ urea and $28 \%$ formamide at the bottom. During electrophoresis, the gels remained immersed in a tank with recirculated buffer held at a constant $60^{\circ} \mathrm{C}$ with a constant temperature circulator. Each percentage denaturant unit is roughly equivalent to $0.3^{\circ} \mathrm{C}$. The equivalent "temperature" is thus $66^{\circ} \mathrm{C}\left[60^{\circ} \mathrm{C} \times\right.$ $\left(0.3^{\circ} \mathrm{C} / \%\right.$ gradient) $(20 \%$ gradient $\left.)\right]$ at the beginning of the gradient and $81^{\circ} \mathrm{C}$ at the end.

To enhance heteroduplex formation, PCR products are boiled for $5 \mathrm{~min}$ and allowed to return gradually to room temperature. DNA (300 ng) is loaded onto a gel. Electrophoresis is carried out at 150 $\mathrm{V}$ for $15 \mathrm{hr}$. Gels are stained with ethidium bromide for visualization of bands 


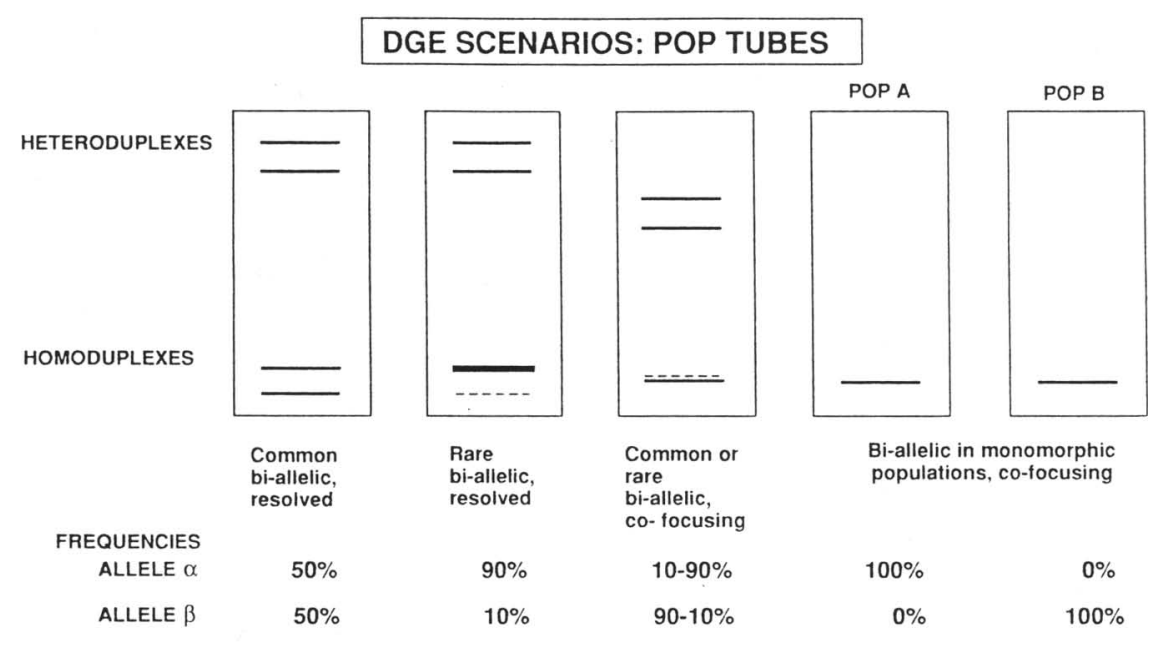

DGE SCENARIOS: U.N. TUBES

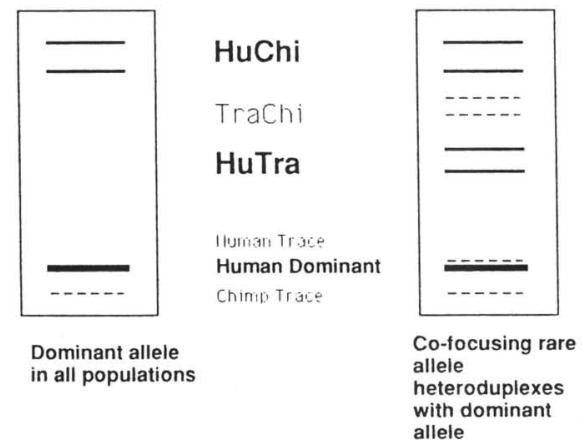

FIGURE 3 Denaturing gradient electrophoresis (DGE) screening scenarios of resolvable or cofocusing alleles for several modes of allelic distribution in populations utilizing the population tube (poptube) system. Panels depict hypothetical DGE gels of poptube and UN-tube products for a bi-allelic polymorphism with variants $\alpha$ and $\beta$. The distribution frequency for each allele is also considered in the diagram, as denoted at the bottom of each gel. (Upper panels) First gel shows a bi-allelic mixture of even distribution with two clearly resolved homoduplexes and two heteroduplexes. Second gel shows the same alleles but in uneven distribution. Third gel shows homoduplexes co-focusing as a single band. The pattern of bands in this case is the same regardless of allele frequency in the poptube. The fourth and fifth gels depict a situation that could be found in some isolated and inbred populations of relatively recent ancestry. Heteroduplex formation would not be expected in a sample containing only five individuals. If another population is similarly inbred and evidences a co-focusing allele, DNA sequence variation could only be detected in UN-tubes. (Lower panels) Two different kinds of heteroduplexes are possible: human trace allele with dominant human allele (HuTra) and chimpanzee allele with dominant human allele (HuChi). In the first panel, no human variant is found; only HuChi is observed. In the second panel, a human variant occurs: both HuTra and HuChi are observed leading to four heteroduplex bands. The heteroduplex between trace human allele and chimpanzee (TraChi) is likely not observed since it is improbable that the two trace elements will hybridize in the presence of a dominant species.

under ultraviolet light. Gels are shown in this paper as photographed. Occasional slanting or curving of the lanes in the gels results from localized dissipation of the gradient to the chamber buffer during electrophoresis.

\section{RESULTS}

The mixed templates of the poptube sys- tem were amplified for the G6PD locus. Products were denatured, reannealed and separated by DGE. Poptubes (1-19) are shown in Figure 4A. Two heteroduplex bands are seen on lane 1, clearly displaced from a single homoduplex band. The single homoduplex band is detected in all samples. Thus, we have discovered a human variant in popula- tion 1, the Biaka Pygmy population, a variant that is rare on a global level.

There are two constant HuChi heteroduplex bands in UN-tubes $1-4$ as well as a monomorphic homoduplex band (Fig. $4 \mathrm{~B}$, left panel). Taken together, these observations demonstrate that the dominant human allele is the same across the world. We performed a mixing experiment (right panel) to validate the HuChi heteroduplex. The reference chimpanzee (Chi) used in all UN-tubes and an individual human $(\mathrm{Hu}) \mathrm{DNA}$ (part of the mixed European population, poptube 14) were amplified separately and each product was run on DGE. There is a clear mobility shift between products, an indication of sequence divergence between the two species for the fragment in question. These products were also mixed, boiled, and allowed to reanneal to form HuChi heteroduplexes. The resulting heteroduplexes are identical to those formed in the pooled DNA sample of tube UN 4. No chimpanzee homoduplex is seen in UN 4 since chimpanzee DNA constitutes a trace allele in the mixture.

We proceeded to identify the individual or individuals in population 1 accounting for the variant detected in the poptube (Fig. 4C). Individual PCR products (A-E) from the five Biaka pygmies pooled in poptube 1 showed no heteroduplex formation (right side of panel). Typing the individuals required pairwise heteroduplex formation as the two alleles are indistinguishable by DGE of the homoduplexes. Sequential pairwise mixing was used: $A B, B C, C D, D E$, EA (left side). This strategy covers the entire set of samples, assays each sample twice as a potential heteroduplex with two different counterparts and allows identification of variants because the mixing experiments are linked sequentially. The pairwise analysis shows heteroduplex formation only in the $\mathrm{BC}$ and $\mathrm{CD}$ pairs, thus, demonstrating that individual $\mathrm{C}$, a male, is hemizygous for the variant sequence. $\mathrm{PCR}$ product from $\mathrm{C}$ is incapable of forming heteroduplex for G6PD, an $\mathrm{X}$-chromosome locus. [The sample from the Biaka Pygmy population contained in the respective $\mathrm{UN}$-tube for that population (UN 1) is A, not C; thus, no variation was detected at that level.]

\section{DISCUSSION}

The detection and survey limits of the poptube system will be dependent on at 
least three factors. The first factor is the extent to which the amplification products from pooled template represent each component genome. Second, the number of individuals included in the poptube should provide a representative sample of the alleles in a population. Finally, the detection limits of gel electrophoresis are of concern.

To examine representation of the
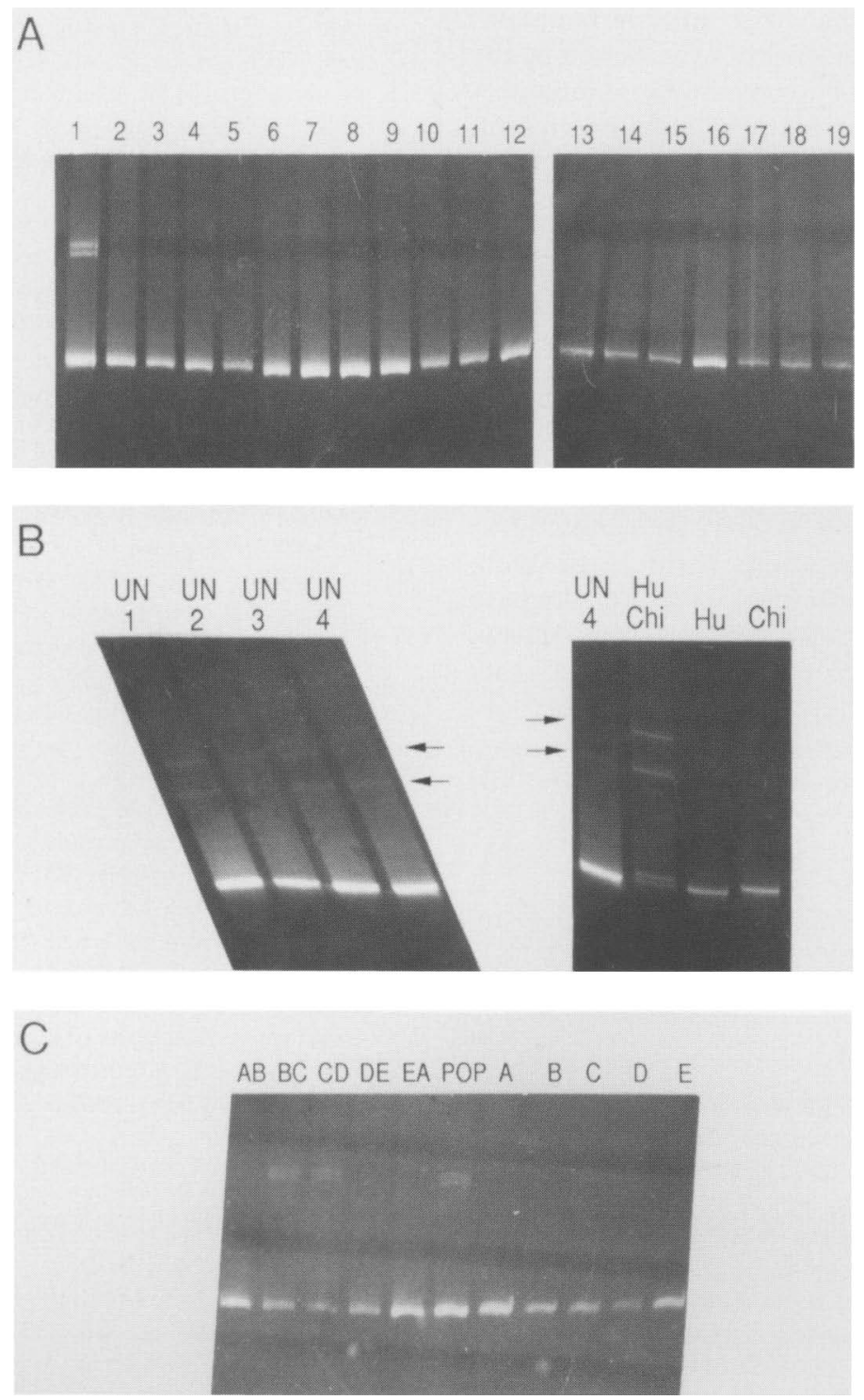

FIGURE 4 Discovery of a rare variant in the long intron of the G6PD gene by population tube screening. (A) The composite template is amplified and products denatured, reannealed, and separated by DGE. Population tubes (1-19) are shown for the 440-bp G6PD locus. A heteroduplex is detected in lane 1, the Biaka Pygmy population. (Refer to Materials and Methods for listing of populations tested.) (B) (Left) UN-tubes 1-4 evidence two constant HuChi heteroduplex bands and a monomorphic homoduplex band. (Right) Mixing experiment to validate HuChi heteroduplex. Chimpanzee (Chi) and human ( $\mathrm{Hu}$ ) DNA were amplified individually and each product was run on DGE. These products were also mixed, boiled, and allowed to reanneal to form HuChi heteroduplexes. The resulting heteroduplexes are identical to those formed in the pooled DNA sample of tube UN 4. No chimpanzee homoduplex is seen in UN 4. (C) Detecting the variant in the five Biaka pygmies pooled in Population tube 1. Individual PCR products $(A-E)$ showed no heteroduplex formation. Further, no shifts are detected among homoduplexes of individual samples. Typing the individuals required pairwise heteroduplex formation as the two alleles are indistinguishable by DGE of the homoduplexes. The pairwise analysis shows heteroduplex formation only in the $B C$ and $C D$ pairs, thus, demonstrating that individual $C$, a male, has the variant.

component alleles when genomic DNA mixtures are amplified en masse, we had performed several analytical mixing experiments with both amplified PCR products and with genomic DNAs. ${ }^{(17)}$ In a related paper, the poptube system was utilized to screen for a polymorphic Alu insertion in the tissue plasminogen activator gene. ${ }^{(19)}$ Pacek et al. ${ }^{(20)}$ have independently employed large-scale pooling of $\sim 1000$ individuals to assess allele frequencies at loci with length polymorphisms. In all three cases, amplification from pooled templates reflected the allele frequencies obtained by individual sampling.

Limiting the size of the pool to five DNA samples limits the number of individual screenings should a variant be found in a pool and speeds up screening. The sampling requirements can be modeled by a binomial distribution if we assume that the population is large and that the sampling of 10 chromosomes through selection of five individuals is truly random. The chances of detecting a variant at least once in a sample of 10 is dependent on the frequency of the allele in the population and can be obtained from standard binomial probability tables. The probability of detection is virtually $100 \%$ if the frequency of the variant in the population is $\$ 30 \%$. At lower frequencies, the probability of detection ranges from $89 \%$ at $20 \%$ frequency to $40 \%$ at $5 \%$ frequency. Thus, the poptube system as implemented is robust enough to detect common alleles $(>25 \%$ frequency). It will miss a fraction of alleles that are only moderately frequent (5-20\% frequency). To detect infrequent alleles occurring at $\leqslant 5 \%$, more than one poptube per population would be needed.

Regular agarose electrophoresis suffices for detection of insertion/deletion heteroduplexes. ${ }^{(9)}$ On the basis of steric hindrance, even highly resolving nondenaturing acrylamide gels may detect heteroduplexes resulting from single base pair mismatches. ${ }^{(21)}$ However, to exploit the inherent instability of heteroduplexes for DNA variation detection, denaturing gradient gels should be utilized. The destabilization afforded by a mismatch in a heteroduplex (as high as $6^{\circ} \mathrm{C}$ ) may be larger than the difference between melting domains in short $(<500$ bp) homoduplex fragments $\left(\leqslant 4^{\circ} \mathrm{C}\right) .{ }^{(22)}$ Heteroduplex DGE may thus allow detection of DNA variants in melt- 
ing domains impossible to examine during DGE of homoduplexes alone.

One further advantage of heteroduplex DGE is that heteroduplexes usually are distinguished clearly above homoduplexes in a denaturing gradient gel even under suboptimal technical conditions. PCR fragments from different loci may be scanned for heteroduplex formation under similar DGE conditions. In our experience, heteroduplex DGE is the most sensitive electrophoretic method for answering the basic question "are two DNA fragments the same sequence?" We have detected single transitions and transversions in 300-bp test fragments fully sequenced independently. ${ }^{(9,17)}$ In one particularly striking example, two closely opposed heteroduplexes (clearly displaced above two homoduplexes) detected a variant found to be a single transition only 15 bases away from one primer (see ref. 9, Fig. 1D). Given the partial single-stranded nature at the ends of PCR products, difficulty in detection of the variant may have been anticipated.

Our result for the G6PD poptube screening is a surprising lack of variation in a noncoding region of the gene. The G6PD result correlates with that of D'Urso et al. ${ }^{(23)}$ who also reported lack of variation with conventional RFLP analysis. Only one polymorphism, a silent transition at the wobble position of a codon, was found and only in contemporary Nigerian, Ghanaian, and West Indian populations. ${ }^{(23)}$ Our single variant in an aboriginal African population also would parallel D'Urso's finding in that African populations seem to have the most variation in a gene apparently invariant in other ethnic groups. It would be interesting to type the G6PD polymorphism found here with that of D'Urso to investigate the possibility of ancient G6PD haplotypes in this geographic location.

Several applications of the poptube system can be anticipated. For instance, pools of families or of sibships could be used to identify families or subships segregating for a given marker in genetic mapping studies. Pools of DNA from patients versus normal individuals could be prepared in molecular scanning of regions presumed to contain mutations. Pools of patients having the same diagnosis but different geographical or ethnic origin could also be employed to ascertain the genetic heterogeneity of inherited disease.
Fuller theoretical modeling of deliberate heteroduplex formation is required to assess its generality and sensitivity. In our hands, the method has proved immensely powerful in detection of DNA sequence variants. ${ }^{(9,17)}$ The poptube system at once benefits from the speed afforded by screening multiple templates and from the sensitivity conferred by the melting behavior of the heteroduplexes that will form if any variants are present.

\section{ACKNOWLEDGMENTS}

Human sequence data for the long G6PD intron containing the 440-bp fragment was kindly communicated to us prior to publication by Dr. Michele D'Urso (Istituto Internazionale di Genetica e Biofisica, Naples, Italy). The Lerman and Frigg melting map program MELT87 was made available to us by Dr. Leonard Lerman (Massachusetts Institute of Technology, Cambridge, MA). Dr. Richard Kouri (BIOS Laboratories, New Haven, CT) lent useful suggestions to the studies. The authors are thankful to these investigators for their contributions.

This research was supported by $\mathrm{NIH}$ grant HG00365 and by NSF grant BNS 8813234 awarded to K.K. Kidd. G. Ruano was a fellow of the Medical Scientist Training Program at Yale University School of Medicine, New Haven, CT.

\section{REFERENCES}

1. Rossiter, B.J.F. and C.T. Caskey. 1990. Molecular scanning methods of mutation detection. J. Biol. Chem. 265: 12753-12756.

2. Ruano, G., J.B. Lichter, and K.K. Kidd. 1993. Normal DNA sequence variation: Detection technologies and implications. In Genome research in molecular medicine and virology (ed. K.W. Adolph), pp. 1-22. Academic Press, San Diego, CA.

3. Myers, R.M., N. Lumelsky, L.S. Lerman, and T. Maniatis. 1985. Detection of single base substitutions in total genomic DNA Nature 313: 495-498.

4. Myers, R.M., Z. Larin, and T. Maniatis. 1985. Detection of single base substitutions by ribonuclease cleavage at mismatches in RNA : DNA duplexes. Science 230: 1242-1246.

5. Myers, R.M. and T. Maniatis. 1986. Recent advances in the development of methods for detecting single-base substitutions associated with human genetic diseases. Cold Spring Harbor Symp. Quant. Biol. 51: 275-284.

6. Cotton, R.G.H., N.R. Rodrigues, and R.D Campbell. 1988. Reactivity of cytosine and thymine in single-base pair mismatches with hydroxylamine and osmium tetroxide and its application to the study of mutations. Proc. Natl. Acad. Sci. 85: 4397-4401.

7. Dianzani, I., S.M. Forrest, C. Camaschella, E. Gottardi, and R.G.H. Cotton. 1991. Heterozygotes and homozygotes: Discrimination by chemical cleavage of mismatch. Am. J. Human. Genet. 48: 423-424.

8. Nagamine, C.M., K. Chan, and Y.F.C. Lau. 1989. A PCR artifact: Generation of heteroduplexes. Am. J. Hum. Genet. 45: 338339.

9. Ruano, G., J. Rogers, A.C. Ferguson-Smith, and K.K. Kidd. 1992. DNA sequence polymorphism within hominoid species exceeds the number of phylogenetically informative characters for a HOX2 locus. Mol. Biol. Evol. 9: 575-586.

10. Kogan, S. and J. Gitschier. 1990. Mutations and a polymorphism in the factor VIII gene discovered by denaturing gradient gel electrophoresis. Proc. Natl. Acad. Sci. 87: 2092-2096.

11. Traystman, M.D., M. Higuchi, C.K. Kasper, S.E. Antonarkis, and H.H. Kazazian. 1990. Use of denaturing gradient gel electrophoresis to detect point mutations in the factor VIII gene. Genomics 6: 293301.

12. Cai, S.P. and Y.W. Kan. 1990. Identification of the multiple $\beta$-thalassemia mutations by denaturing gradient gel electrophoresis. I. Clin. Invest. 85: 550-553.

13. Sung, C.H., C.M. Davenport, J.C. Hennessey, K.H. Maumenee, S.G. Jacobson, J.R. Heckenlively, R. Nowakowski, G. Fishman, P. Gouras, and J. Nathans. 1991. Rhodopsin mutations in autosomal dominant retinitis pigmentosa. Proc. Natl. Acad. Sci. 88: 6481-6485.

14. Sheffield, V.C., D.R. Cox, L.S. Lerman, and R.M. Myers. 1989. Attachment of a 40-base-pair G + C-rich sequence (GCclamp) to genomic DNA fragments by the polymerase chain reaction results in improved detection of single-base changes. Proc. Natl. Acad. Sci. 86: 232-236.

15. Soto, D. and S. Kumar. 1992. Improved detection of mutations in the $\mathrm{p} 53$ gene in human tumors as single-stranded conformation polymorphs and double-stranded heteroduplex DNA. PCR Methods Applic. 2: 96-98.

16. Beck, J.S., A.E. Kwitek, P.H. Cogen, A.K. Metzger, G.M. Duyk, and V.C. Sheffield. 1993. A denaturing gradient gel electrophoresis assay for sensitive detection of p53 mutations. Hum. Genet. 91: 25-30.

17. Ruano, G. and K.K. Kidd. 1992. Modeling of heteroduplex formation during PCR from mixtures of DNA templates. $P C R$ Methods Applic. 2: 112-116.

18. Ruano, G. 1992. "A PCR-based paradigm for the analysis of DNA sequence variation." Ph.D. thesis, Yale University, New 
Haven, CT.

19. Tishkoff, S., G. Ruano, and K.K. Kidd. 1993. A global analysis of the distribution and frequency of a polymorphic Alu insertion at the PIAT locus in humans. Am. J. Hum. Genet. (Suppl.) 53: Abstr. 870.

20. Pacek, P., A. Sajantila, and A. Syvanen. 1993. Determination of allele frequencies at loci with length polymorphism by quantitative analysis of DNA amplified from pooled samples. PCR Methods Applic. 2: 313-317.

21. Triggs-Raine, B.L. and R.A. Gravel. 1990. Diagnostic heteroduplexes: Simple detection of carriers of a 4-bp insertion mutation in Tay-Sachs disease. Am. J. Hum. Genet. 46: 183-184.

22. Myers, R.M., V.C. Sheffield, and D.R. Cox. 1988. Detection of single base changes in DNA: Ribonuclease cleavage and denaturing gradient gel electrophoresis. In Genomic analysis (ed. K.E. Davies), pp. 95139. IRL Press, Oxford.

23. D'Urso, M., L. Luzzatto, L. Perroni, A. Ciccodicola, G. Gentile, I. Peluso, M.G. Perisco, T. Pizzella, D. Toniolo, and T.J. Vulliamy. 1988. An extensive search for RFLP in the human glucose-6-phosphate dehydrogenase locus has revealed a silent mutation in the coding sequence. Am. J. Hum. Genet. 42: 735-741.

Received October 5, 1993; accepted in revised form December 21, 1993. 


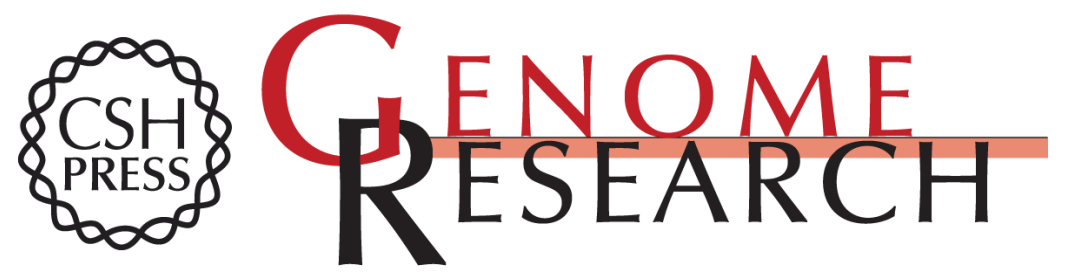

\section{Detection of DNA sequence variation via deliberate heteroduplex formation from genomic DNAs amplified en masse in "population tubes".}

G Ruano, A S Deinard, S Tishkoff, et al.

Genome Res. 1994 3: 225-231

References This article cites 19 articles, 7 of which can be accessed free at:

http://genome.cshlp.org/content/3/4/225.full.html\#ref-list-1

License

Email Alerting Service

Receive free email alerts when new articles cite this article - sign up in the box at the top right corner of the article or click here.

\section{Affordable, Accurate Sequencing.}

To subscribe to Genome Research go to:

https://genome.cshlp.org/subscriptions 